\title{
A Review Of Eclampsia At The Lagos University Teaching Hospital (LUTH), Lagos, Nigeria: Have We Improved?
}

\author{
Babah O A ${ }^{1}$, Oluwole A A ${ }^{2}$, Afolabi B B ${ }^{2}$, Odum C $\mathrm{U}^{2}$ \\ ${ }^{1}$ Department of Obstetrics \& Gynaecology, Lagos University Teaching Hospital, PMB 12003, Idi-Araba, \\ Surulere, Lagos, Nigeria \\ ${ }^{2}$ Department of Obstetrics \& Gynaecology, Faculty of Clinical Sciences, College of Medicine, University of \\ Lagos/ Lagos University Teaching Hospital, Lagos, Nigeria
}

\begin{abstract}
A total of 12,234 patients were treated in the Lagos University Teaching Hospital (LUTH) for various obstetric conditions between January 1, 1996 and December 31, 2005. Of these, 165 (1.35\%) were eclamptics. 148 (89.7\%) of these were pre-delivery eclamptics and 17 (10.3\%) were post-delivery eclamptics. Unbooked eclamptics remained a dominant group comprising 149 (90.3\%) of all eclamptics. Mean maternal age was $26.59 \pm 0.44$ years. Most of these patients were of low parity; primiparae constituting $76.8 \%$ and multiparae $23.2 \%$. Mean gestational amenorrhoea at onset of eclampsia being $34.64 \pm 0.44$ weeks. There were 22 maternal deaths due to eclampsia and its complications with a maternal mortality rate of 133.3 per 1000 eclamptics. The commonest causes of maternal deaths were septicaemia (13.64\%), acute renal failure (9.09\%) and respiratory failure (9.09\%). There were 54 perinatal deaths, with a perinatal mortality rate of 346.2 per 1000.

A comparison of the data obtained from this recent decade (1996 - 2005) to those of the previous three decades (1967 - 1976, 1977 - 1986 and 1986 - 1995) showed that there had been a progressive decline in the number of eclamptics managed in LUTH in the last three decades (572 eclamptics in 1977 - 1986, 299 eclamptics in 1986 - 1995, and 165 in 1996 - 2005). This study also showed a rise in the mean caesarean section rate for predelivery eclamptics and all eclamptics (55.41\% and $49.70 \%$ respectively) compared to findings in the previous decades. There was a significant increase in the maternal mortality and perinatal mortality rates in recent decade. There was a decline in post mortem rate $140.9 \%$ in recent decade compared with $60 \%$ in previous decades).
\end{abstract}

Key words: Eclampsia in Lagos, maternal deaths, perinatal deaths.

\section{Introduction}

The Lagos University Teaching Hospital (LUTH) is the largest tertiary health institution in Lagos, Nigeria and it caters for patients referred from various private and government health facilities in Lagos. Eclampsia is a common obstetric emergency all over Nigeria and it is a common cause of maternal and perinatal deaths. The obstetric unit of LUTH has a special interest in the management of this condition and has been involved in its management for over four decades.

On a 10 yearly basis, retrospective studies are carried out, to review all the eclamptics managed in LUTH in order to have an overview of the clinical profile and prognostic outcome of the disease, associated complications and causes of maternal deaths and its effect on perinatal mortality. By so doing, we are able to assess the efficacy of our treatment protocols.

This was a retrospective study of all eclamptics managed in LUTH between January 1, 1996 and December 31, 2005. It was a follow up to previous studies and publications in the last three decades (1967 1976, 1977 - 1986 and 1986 - 1995), as the hospital conducts a review on eclamptic women managed on a 10yearly basis. A comparison of findings in all the four decades were made.

It is also important to note that a periodic review of the prognostic outcome in eclamptics managed in LUTH is essentially because over time modalities of treatment has remained the same and these include immediate control of seizures, control of hypertension and prompt delivery where indicated. However the drugs used in control of seizures and hypertension have changed over time.

\section{Materials And Methods}

Diagnosis of eclampsia was based on strict criteria of occurrence of at least an episode of seizure in a pregnant woman with features of pre-eclampsia. All the cases studied met these criteria as most of these women were in their third trimesters, had blood pressures elevated to variable levels, proteinuria and some had oedema. Others causes of seizures such as epilepsy were excluded before diagnosis were made.

In previous decades drugs used included rectal bromethol (1967 - 1969), lytic cocktail with minimal use of parenteral hypotensive agents (1969 - 1972), chlomethiazole (1972 - 1976) and chlomethiazole in 
A Review Of Eclampsia At The Lagos University Teaching Hospital (Luth), Lagos, Nigeria: Have

addition to more frequent use of intramuscular reserpine and/or intravenous hydrallazine $(1977-1986)^{1}$. While in 1986 - 1995, diazepam infusion with intramuscular reserpine and/or intravenous hydrallazine were used for control of seizures and hypertension respectively ${ }^{4}$. During this study period (1996 - 2005), intravenous diazepam infusion and magnesium sulphate were used for control of seizures while intravenous hydrallazine was the drug of choice in blood pressure control.

For this study, records of all eclamptics managed in LUTH between January 1, 1996 and December 31, 2005 were obtained from the major channels of admission namely the accident and emergency, labour ward and postnatal wards. These were cross-checked with information retrieved at the main records registry. Traceable case notes were retrieved (however quite a number of case notes were not traceable as some of the old case notes had been withdrawn from the records due to overloading of the file racks).

Causes of maternal deaths were ascertained and cross-checked with records and autopsy findings in the death register at the morbid anatomy department. Records of foetal outcome and neonatal deaths were obtained from the labour ward delivery register and the neonatal admissions register in the neonatology unit.

Data obtained were scrutinized and analyzed on a yearly basis. Findings were then compared with earlier studies carried out in the previous three decades in LUTH. These were subjected to statistical analysis. Standard error of mean (SEM) was used to calculate the true mean of closely related data while chi-square $\left(\varkappa^{2}\right)$ test was used to determine if there is significant difference in the overall trends of maternal and perinatal mortality in eclampsia between the periods under study.

\section{Results}

I. Clinical profile: A total of 12,234 patients were treated in LUTH labour ward for various obstetric conditions between January 1, 1996 and December 31, 2005 (table I). Of these, 165 were eclamptics, making the prevalence of eclampsia $1.35 \% .148(89.7 \%)$ of these were pre-delivery eclamptics and 17 $(10.3 \%)$ were post-delivery eclamptics. Unbooked patients were 149 in number, constituting $90.3 \%$ while booked patients numbered $16(9.7 \%) .105$ cases $(63.6 \%)$ occurred during the rainy season and 60 (36.4\%) occurred during dry season. The Mean Maternal Age of these patients was $26.59 \pm 0.44$ years. $76.8 \%$ were primiparae while $23.2 \%$ were multiparae (table II).

The peak gestational age at development of eclampsia in this series was estimated to be $30-40$ weeks as shown in the scatter chart below (figure 1) while the Mean Gestational Amenorrhoea was $34.64 \pm 0.44$ weeks.

II. Mode of delivery: In this series, 148 patients were pre-delivery eclamptics. Of these $82(55.41 \%)$ had caesarean section for various obstetric conditions while 63 (42.57\%) had vaginal delivery. 3 of these patients $(2.03 \%)$ died undelivered.

Of those who had vaginal delivery, $15(23.81 \%)$ were spontaneous, $41(65.08 \%)$ were forceps delivery, $5(7.94 \%)$ had vacuum delivery and $2(3.17 \%)$ had craniotomy. Mean duration of labour in those who delivered vaginally was 10 hours 56 minutes.

Of those who had caesarean section, $71(86.59 \%)$ had surgery under general anaesthesia while 11 patients (13.41\%) had regional anaesthesia.

III. Maternal deaths: During the period under study, there were a total of 22 maternal deaths due to eclampsia and its complications, with a maternal mortality rate of 133.3 per 1000 eclamptics. All the eclamptics who died were unbooked patients. The commonest causes of death during this study period (1996 - 2005) were septicaemia (13.64\%), acute renal failure (9.09\%) and respiratory failure (9.09\%), (table III).

IV. Perinatal deaths: A total of 156 babies were delivered by pre-delivery eclamptics in this series with $112(95.7 \%)$ admitted into the neonatal unit. Birth asphyxia, prematurity and low birth weight were the commonest indications for neonatal admissions. There were 54 perinatal deaths, with a perinatal mortality rate of 346.2 per 1000 eclamptic deliveries. 50 (92.6\%) of the perinatal deaths were from unbooked eclamptics. Major causes of perinatal mortality were prematurity and birth asphyxia. When compared with maternal age, it was found that most of these perinatal deaths occurred amongst eclamptic women aged $20-25$ years (37.0\%), followed closely by those aged $26-30$ years (table IV).

V. Comparative study: When recent findings $(1996$ - 2005) were compared with those in the previous three decades (1967 - 1976, 1977 - 1986 and 1986 - 1995), it was found that there had been a progressive decline in the number of eclamptics managed in LUTH since 1977. A total of 572 were managed in 1977 - 1986, 299 cases were managed in 1986 - 1995 and 165 cases in $1996-2005$. Prevalence had dropped from 16.8/1000 deliveries in 1986 - 1995 to 13.5/1000 deliveries in 1996 2005.

There was a rise in the maternal and perinatal mortality rates. Maternal mortality rate was 93.6/1000 in 1986 - 1995 and 133.3/1000 in 1996 - 2005. Perinatal mortality rate was 137.8/1000 in 1986 - 1995; this had more than doubled in recent decade, being 346.2/1000 in $1996-2005$. 
A Review Of Eclampsia At The Lagos University Teaching Hospital (Luth), Lagos, Nigeria: Have

There had also been a progressive increase in caesarean section rate in both pre-delivery eclamptics and all eclamptics. For pre-delivery eclamptics, caesarean section rate was $21.3 \%$ in $1967-1976,30.2 \%$ in $1977-$ 1986, 47.3\% in 1986 - 1995 and $55.41 \%$ in this recent decade (1996 - 2005). Table V shows a summary of the pattern of eclampsia in the last four decades under review.

Post mortem rate dropped from 60\% in the previous three decades to $40.9 \%$ in this recent decade (1996 - 2005). In all series, unbooked eclamptics remained a dominant group, with most eclampsia occurring predelivery and in the third trimester, with a significant proportion of affected women being primigravidae. The relationship between perinatal deaths in eclampsia and maternal age remained unchanged in all series (table IV). The histogram below (figure 2) gives a pictorial representation of findings in the last four decades (1967 2005).

Using chi square $\left(x^{2}\right)$ test, it was found that there was no statistical significant difference in maternal deaths between the four decades studied $\left(\mathcal{X}^{2}=1.7553, \mathrm{p}<0.05\right)$. However, there was a statistically significant difference in perinatal deaths between these four decades $\left(x^{2}=28.7205\right.$, $\left.\mathrm{p}<0.05\right)$.

Table I: Labour wards admissions (1996 - 2005).

\begin{tabular}{|l|c|l|}
\hline YEAR & TOTAL ADMISSIONS & TOTAL ECLAMPTICS \\
\hline $\mathbf{1 9 9 6}$ & 1,331 & 57 \\
\hline $\mathbf{1 9 9 7}$ & 1,062 & 21 \\
\hline $\mathbf{1 9 9 8}$ & 1,522 & 14 \\
\hline $\mathbf{1 9 9 9}$ & 1,101 & 10 \\
\hline $\mathbf{2 0 0 0}$ & 1,252 & 13 \\
\hline $\mathbf{2 0 0 1}$ & 1,253 & 12 \\
\hline $\mathbf{2 0 0 2}$ & 1,160 & 19 \\
\hline $\mathbf{2 0 0 3}$ & 1,556 & 10 \\
\hline $\mathbf{2 0 0 4}$ & 1,069 & 5 \\
\hline $\mathbf{2 0 0 5}$ & 928 & 4 \\
\hline TOTAL & 12,234 & 165 \\
\hline
\end{tabular}

Table II: Clinical profile in eclampsia (1996 - 2005).

\begin{tabular}{|l|l|}
\hline CLINICAL PROFILE & NO. $(\boldsymbol{\%})$ \\
\hline Total labour ward admissions & 12,234 \\
\hline Eclampsia (all types) & $165($ prevalence=1.35\%) \\
\hline Pre-delivery & $148(89.7)$ \\
\hline Post-delivery & $17(10.3)$ \\
\hline Unbooked & $149(90.3)$ \\
\hline Booked & $16(9.7)$ \\
\hline Mean age of subjects & $26.59 \pm 0.44$ years \\
\hline Age range of subjects & $16-40$ years \\
\hline Primiparae & $119(76.8)$ \\
\hline Multiparae & $36(23.2)$ \\
\hline Mean gestational amenorrhoea for pre-delivery eclamptics & $34.64 \pm 0.44$ weeks \\
\hline
\end{tabular}

*Note: Figures in parenthesis are in percentages.

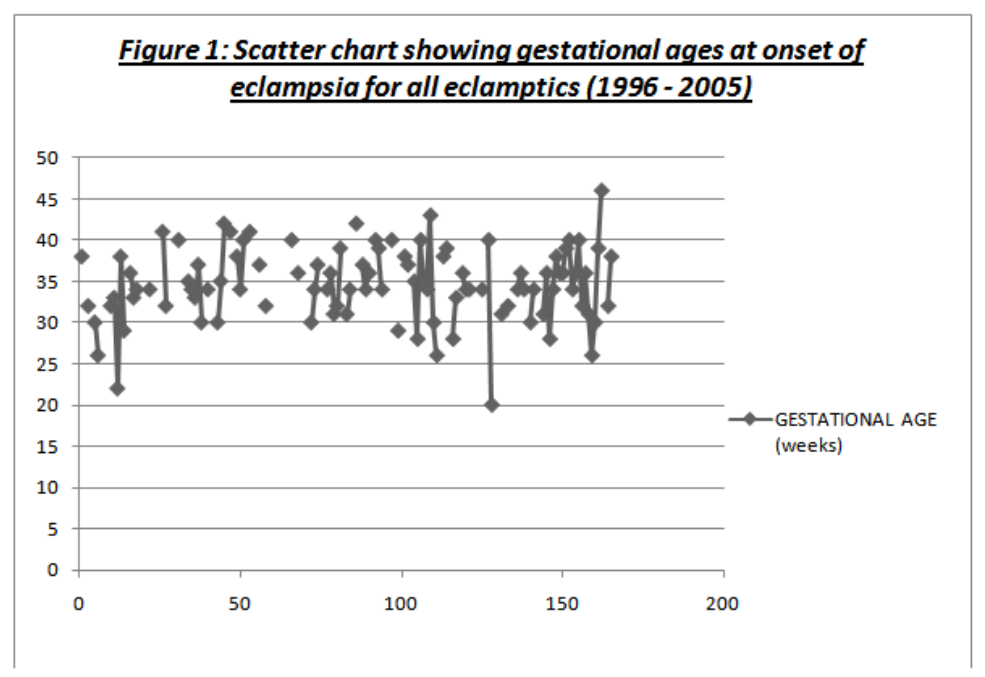


A Review Of Eclampsia At The Lagos University Teaching Hospital (Luth), Lagos, Nigeria: Have

Table III: Complications and causes of maternal deaths in eclampsia (1996 - 2005).

\begin{tabular}{|l|l|l|}
\hline CAUSE OF DEATH & NO & $\%$ \\
\hline Cerebral oedema/tonsillar herniation & 1 & 4.55 \\
\hline Intraventricular/subarachnoid haemorrhage & 1 & 4.55 \\
\hline Pulmonary collapse/respiratory failure & 2 & 9.09 \\
\hline Hypovolaemic shock & 1 & 4.55 \\
\hline Acute renal failure & 2 & 9.09 \\
\hline Puerperal sepsis & 1 & 4.55 \\
\hline Disseminated intravascular coagulation & 1 & 4.55 \\
\hline Septicaemia & 3 & 13.64 \\
\hline Anaemic heart failure & 1 & 4.55 \\
\hline HELLP syndrome & 1 & 4.55 \\
\hline Post partum haemorrhage & 1 & 4.55 \\
\hline Unspecified primary cause of death other than eclampsia & 7 & 31.82 \\
\hline
\end{tabular}

Only 9 of the eclamptics that died had post mortem examination; hence maternal post mortem rate was $40.9 \%$.

Table IV: Perinatal deaths in relation to maternal age of eclamptics.

\begin{tabular}{|l|l|l|l|c|}
\hline AGE (years) & $\mathbf{1 9 6 7 - 1 9 7 6}$ & $\mathbf{1 9 7 7 - 1 9 8 6}$ & $\mathbf{1 9 8 6 - 1 9 9 5}$ & $\mathbf{1 9 9 6 - 2 0 0 5}$ \\
\hline$<\mathbf{2 0}$ & $13(23.6)$ & $11(11.0)$ & $8(18.66)$ & $8(14.8)$ \\
\hline $\mathbf{2 0}-\mathbf{2 5}$ & $29(52.7)$ & $48(48.0)$ & $18(41.86)$ & $20(37.0)$ \\
\hline $\mathbf{2 6}-\mathbf{3 0}$ & $7(12.7)$ & $25(25.0)$ & $9(20.9)$ & $13(24.1)$ \\
\hline $\mathbf{3 1}-\mathbf{3 5}$ & $3(5.5)$ & $13(13.0)$ & $3(6.98)$ & $9(16.7)$ \\
\hline $\mathbf{3 6}-\mathbf{4 0}$ & $3(5.5)$ & $3(3.0)$ & $3(6.98)$ & $4(7.4)$ \\
\hline$>\mathbf{4 0}$ & $0(0.0)$ & $0(0.0)$ & $2(4.65)$ & $0(0.0)$ \\
\hline TOTAL & 55 & 100 & 43 & 54 \\
\hline
\end{tabular}

*Note: Figures in parenthesis are in percentages.

Table V: Pattern of eclampsia in the last four decades (1967 -2005)

\begin{tabular}{|c|c|c|c|c|}
\hline CLINICAL PROFILE & 1967-1976 & 1977-1986 & 1986-1995 & 1996-2005 \\
\hline Total number of eclamptics & 273 & 572 & 299 & 165 \\
\hline Maternal Mortality Rate (per 1000) & 106 & 108 & 93.6 & 133.3 \\
\hline Perinatal Mortality Rate (per 1000) & 117 & 240 & 137.8 & 346.2 \\
\hline C/S rate - all eclamptics $(\%)$ & 10.62 & 22.2 & & 49.7 \\
\hline C/S rate - predelivery eclamptics (\%) & 21.3 & 30.2 & 47.3 & 55.4 \\
\hline Post Mortem Rate (\%) & & 60 & 60.7 & 40.9 \\
\hline Prevalence (per 1000 deliveries) & & & 16.8 & 13.5 \\
\hline Unbooked eclamptics (\%) & 87.9 & 78.3 & 94 & 90.3 \\
\hline Predelivery eclamptics (\%) & & & 67.9 & 89.7 \\
\hline Post delivery eclamptics (\%) & & & 32.1 & 10.3 \\
\hline Primigravidae (\%) & & & 63.5 & 76.8 \\
\hline Multigravidae (\%) & & & 36.5 & 23.2 \\
\hline $\begin{array}{l}\text { Mean gestational amenorrhoea } \pm \text { SEM } \\
\text { (weeks) }\end{array}$ & & $36.7 \pm 0.15$ & $35.04 \pm 0.5$ & $34.64 \pm 0.44$ \\
\hline Mean maternal age \pm SEM (years) & & $24.0 \pm 0.22$ & $24.58 \pm 0.76$ & $26.65 \pm 0.44$ \\
\hline
\end{tabular}




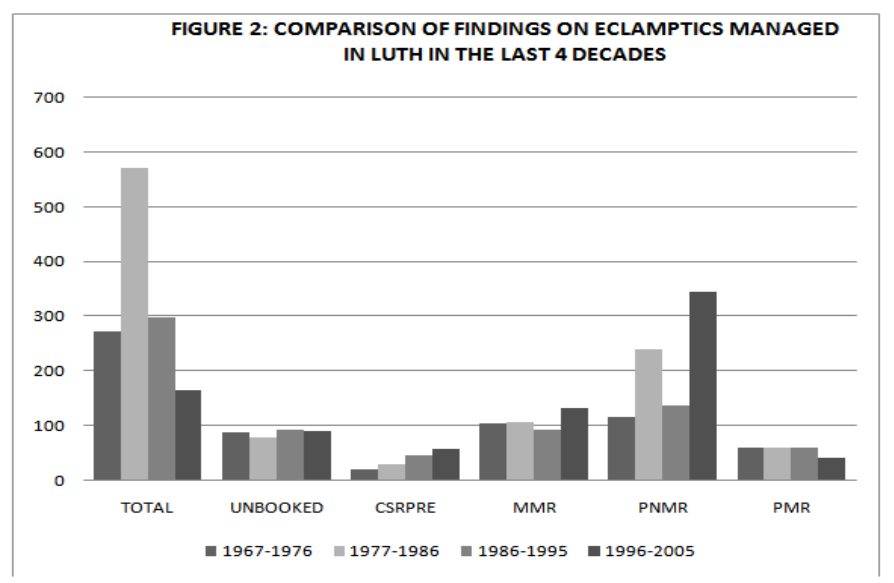

*Note:

TOTAL $=$ total number of eclamptics that were managed per decade.

UNBOOKED = percentage of total eclamptics that were unbooked patients.

CSRPRE = caesarean section rate for predelivery eclamptics (in \%).

MMR = maternal mortality rate per 1000 eclamptics.

PNMR = perinatal mortality rate per 1000 eclamptic deliveries.

$\mathrm{PMR}=$ post mortem rate for dead eclamptics (\% of total maternal deaths).

\section{Discussion}

This study highlights the pattern of eclampsia in the recent decade (1996 - 2005). In this series, prevalence of eclampsia was $1.35 \%$ in Lagos, Nigeria. This is comparable to a prevalence of $1.32 \%$ obtained in Benin City, Nigeria around same study period (1995 - 2002) ${ }^{5}$. However, prevalence varies from one geographical location to the other, being as low as $0.29 \%$ in Qatar ${ }^{6}$ and as high as $2.27 \%$ in India ${ }^{7}$. Most of the patients in this series $(63.6 \%)$ developed eclampsia during rainy season. This is similar to other studies associating eclampsia with lower temperatures $\mathbf{8 , 9 , 1 0}$.

When the number of eclamptics treated in LUTH in the recent 10 years was compared on a yearly basis, it was found that very few eclamptics were treated in 2004 and 2005 (5 and 4 cases respectively). However when compared with the total number of deliveries on a yearly basis, it was found that there was also a reduction in the total number of deliveries. This reduction in number of patients presenting in LUTH was as a result of the industrial actions by health workers during this period.

It was also observed that there is a reduction in prevalence of eclampsia in recent decade. This may be attributed to the fact that there had been an upgrading of health facilities within Lagos metropolis in the recent decade, for instance, new teaching hospitals like the Lagos State University Teaching Hospital, LASUTH were created and quite a number of state owned health centres were converted to General Hospitals in the last decade. These health institutions had helped in reducing the patient load in LUTH.

This study also compares recent findings with those in the previous three decades $(1967$ - 1976, 1977 1986 and 1986 - 1995). The clinical profile had however remained unchanged, as most of these patients were unbooked, young women below 25 years, of low parity (mostly primigravidae), presenting near term with features of eclampsia and most of these eclampsia occuring predelivery. This had been a consistent pattern in studies carried out in various socio-demographic areas in Nigeria ${ }^{11,12,13,14}$.

There was a progressive rise in the caesarean section rate due to the need for immediate delivery in this category of women, who are mostly unbooked patients. The caesarean section rate of $55.4 \%$ for predelivery eclamptics is similar to 54\% obtained in a study in Qatar (1991 - 2003).

Magnesium sulphate, the main anticonvulsant currently recommended for use in seizure control in eclampsia by the World Health Organization and the Royal College of Obstetricians and Gynaecologists, was used during the later part of this recent decade (1996 - 2005) and was found to be beneficial in seizure control, as virtually all patients who had magnesium sulphate were seizure-free after commencement of the medication.

Despite concerted efforts towards reducing maternal and perinatal morbidity and mortality in eclamptics, there had been an increase in the maternal and perinatal mortality rates in recent decade. The only reason attributed for this increase being that these patients were unbooked and they presented in very poor clinical state. Although there was a statistical significant difference in perinatal deaths over the four decades under study, the perinatal mortality rate in the recent decade is comparable to what obtains in some third world 
countries like Pakistan $(33.1 \%)^{\mathbf{1 5}}$. This study however, shows that there was no statistical significant difference in maternal deaths over the last four decades in LUTH.

There was a reduction in the post mortem rate in recent decade (from $60 \%$ to $40.9 \%$ ). This was basically due to religious and socio-cultural reasons. There is thus a need to improve awareness amongst people of advantages of autopsy as this will also improve our knowledge on the disease process and give room for improvement in our management guidelines.

In the recent decade, septicaemia was the commonest cause of maternal death in eclampsia, followed by acute renal failure and respiratory failure. While in the previous series (1986 - 1995), disseminated intravascular coagulation (DIC) and cardiac failure topped the list, followed by acute renal failure and pulmonary failure. The increase in the number of patients developing septicaemia is probably due to the fact that many of these eclamptics had been earlier managed in unhygienic conditions in small private health facilities, maternity homes and churches, by untrained personnel and for several days before being referred to LUTH in poor clinical states. Management of complications in eclampsia requires a prompt and multidisciplinary approach as this will go a long way in reducing morbidity and mortality associated with the disease.

\section{Conclusion}

Reduction of morbidity and mortality associated with eclampsia remains a challenge. We are yet to effectively combat this problem due to late referral of cases, poor transportation network and poor funding of the health sector. Health education of women as regards need for regular ante-natal care is absolutely important as various studies have shown eclampsia to be commoner in unbooked patients. Health care providers should have a high index of suspicion and should also know their limitations when managing these patients as this will enhance early referral of cases when the need arise. Role of government in developing the health sector is also an important factor in reducing the morbidity and mortality associated with eclampsia and thus increasing our potential towards achieving the Millennium Development Goals (MDG 3 - Maternal Health and MDG 4 Child Health).

\section{Acknowledgement}

We wish to express our sincere appreciation to all members of staff of morbid anatomy department, the labour ward and records unit for granting us unrestricted access to the records used in carrying out this study.

\section{References}

[1]. Odum CU, Akinkugbe A. The causes of Maternal Deaths in Eclampsia in Lagos, Nigeria. West Afr J Med. 1991 ; 10 (1):371 - 6.

[2]. Odum CU. Eclampsia: An Analysis of 845 Cases Treated in the Lagos University Teaching Hospital, Nigeria Over a 20-year Period. J Obst Gyn East Cent Afr. 1991; 9:16 - 20.

[3]. Odum CU, Akinkugbe A, Emuveyan EE. Mortality in Eclampsia in the Lagos University Teaching Hospital (LUTH); Comparison of the recent 10-year period (1967 - 1976). West Afr J Med. 1990; 9(3):157 - 163.

[4]. Odum CU, Ohaya NI. A Follow up Study of Eclampsia in Lagos 1986 - 1995. Nig Qt J Hosp Med. 1997; 7(1): 25 - 28.

[5]. Onuh SO, Aisien AO. Maternal and foetal outcome in eclamptic patients in Benin City, Nigeria. J Obstet Gynaecol. 2004; 24(7) 765 -8 .

[6]. Shamma T. Al Inizi, Hussain Sharara, Badreldeen Ahmed. Eclampsia in Qatar: Maternal and Fetal Outcomes, Possible Preventive Measures. The Middle East Journal of Emergency Medicine. 2005; 5(1).

[7]. Arati Biswas, Rupali Modak, Saibal Baksi, Sanat Biswas. Epidemiological study of eclampsia in a referral teaching hospital. Journal of Indian Medical Association. 2005; 103(6):323 - 4, 326

[8]. Neela J, Raman L. Seasonal trends in occurrence of eclampsia. Natl Med J India. 1993; 6(1):17- 8.

[9]. Neutral R. Meteorological factors and eclampsia. J Obstet Gynaecol Br Commonw. 1974; 81(11):833 - 40.

[10]. Agobe JT, Good W, Hancock KW. Meteorological relations of eclampsia in Lagos, Nigeria. Br. J Obstet Gynaecol. 1981; 88(7):706 -10 .

[11]. Oladokun A, Okewole AI, Adewole IF, Babarinsa IA. Evaluation of cases of eclampsia in UCH, Ibadan over a 10-year period. West Afr J Med. 2000; 19(3):192 - 4.

[12]. Onwuhafua PI, Onwuhafua A, Adze J, Mairami Z. Eclampsia in Kaduna State of Nigeria - a proposal for a better outcome. Niger J Med. 2001; 10(2):81-4.

[13]. Ozumbia BC, Ibe AI. Eclampsia in Enugu, eastern Nigeria. Acta Obstet Gynecol Scand. 1993; 72(3):189 - 92.

[14]. Igberase GO, Ebeigbe PN. Eclampsia: a ten-years of experience in a rural tertiary hospital in the Niger Delta, Nigeria. J Obstet Gynaecol. 2006; 26(5): $414-417$.

[15]. Jamelle RN. Eclampsia - a taxing situation in the Third World. Int J Gynaecol Obstet. 1997; 58(3):311-2. 